\title{
Planning the 21st Century City - Four Snapshots for a New Science
}

\author{
Michael Batty ${ }^{1^{*}}$ \\ ${ }^{1}$ Centre for Advanced Spatial Analysis, University College London \\ * Corresponding Author, Email: m.batty@ucl.ac.uk
}

Key words: Science, City transitions, Big data, Computer models, Urban planning

Abstract: Demographic growth and the continued evolution of cities call for a new approach to better observe and research our understanding of cities. A new science based on big data, urban modelling and network theory is emerging, providing a different and rather new perspective for planners and decision-makers so that they might learn about both current and future cities. In this article, the new science is briefly introduced from four aspects: Aggregate dynamics; Form and function; High frequency cities; and New tools \& techniques for planning. Examples are given to show how this new science illustrates the real-time city, as well as the structure and functional boundaries of a city, while future practice and further exploration of this new science in urban planning and policy making are explored.

This is an abridged version of the longer presentation given to the National Planning Conference in Fuzhou September 2018

\section{INTRODUCTION}

First of all, let's talk about the contents of this topic. What do I mean by Science in the title? In this context, it stands for Systems, their Closure, Complexity and Behaviour. I mention it here as it stands for a new science of understanding and planning cities which we are rapidly developing at present. It is a science of behaviour and the space-economy and how we can generalize this; it isn't really about materials, or biologies or hydrodynamics; it is much more about information in contrast to energy. It is about flows and connectivity, that is about who relates to who through networks. It is not about smart cities as such although there are strong links to this. Based on the evolution of planning research and practice, this new science for the 21st century city contain the following four aspects which we will deal with here and are based on:

- Aggregate Dynamics, focused on explaining the transitions in cities, the organisation of systems of cities, their population locations and city size;

- Form and Function, which is focused on explaining the structure of city systems, energy, information, connectivity and networks; 
- High frequency cities, focused on recognizing the fine scale temporal change in our cities, and the emergence of what are now called smart cities;

- Tools \& Techniques for Planning, which are focused on solving planning issues by using and developing this science.

For a long period, when we have engaged in urban research, we have usually considered questions such as what happens when cities get bigger? How are cities structured in terms of space? The former is about urban growth and the latter is about the form of our cities. We have worked hard to answer the above two questions, especially with the sciences of information technology, and we have begun to use computers to calculate, compute, and model the city and its future. Computers can also be used to s look at cities in the very short term and how can we use them to bring this science to a wider constituency? And moreover, how can we engage policy makers in using this science? To an extent, this is about form following function. But as we shall see, Louis Sullivan's mandate for the modern movement is fast being replaced with the mantra that 'form never follows function' or only rarely does it so in a digital world. Currently this science draws on complexity theory partly, and this is important because it replaces the old model of the city as a machine with one which considers the city to be an organism. It is about bottom up thinking, about evolution, emergence and path dependence: history matters. It is no longer about system closure but about openness and this is an enormous challenge. Saskia Sassen (2017) said in a recent talk on urban sustainability in Shanghai in 2017 "Cities are complex but incomplete systems". They probably always will be and this makes this science I am imagining very different from physics or economics or even architecture and even the physical world isn't closed. So this science is about many things we have always worked upon but suddenly people are beginning to link together what scale, and density and force and size and mass and hierarchy etc. mean when it comes to cities. So, let's digress from these generalities and first set the context to what this sort of approach can say about growth, change and population transition.

\section{AGGREGATE DYNAMICS - TRANSITIONS}

To relate this to how cities are changing which is the focus over many centuries which have led to the contemporary city, let me begin with population growth a long way back, from more than 10,000 years ago, the end of the last ice age, from the time when mankind moved from a nomadic existence to settled agriculture.

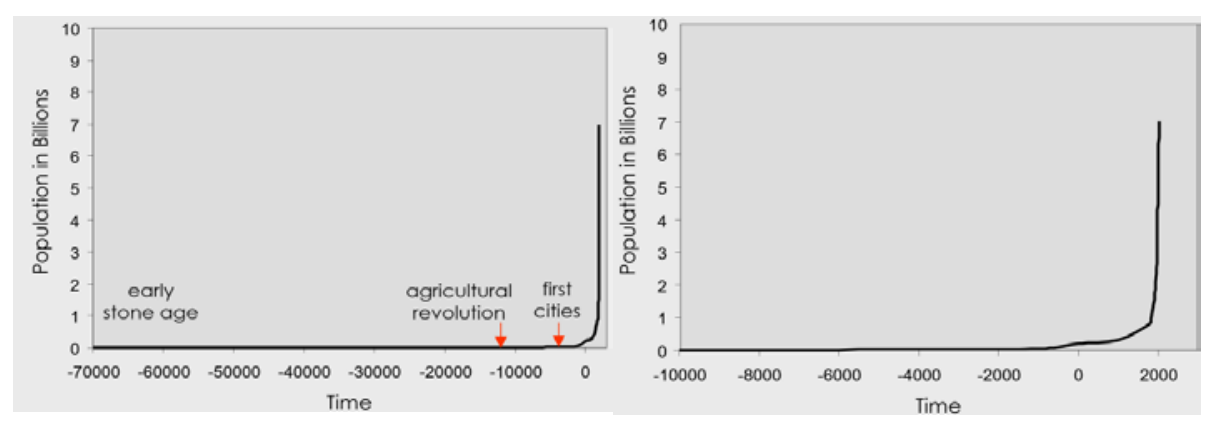



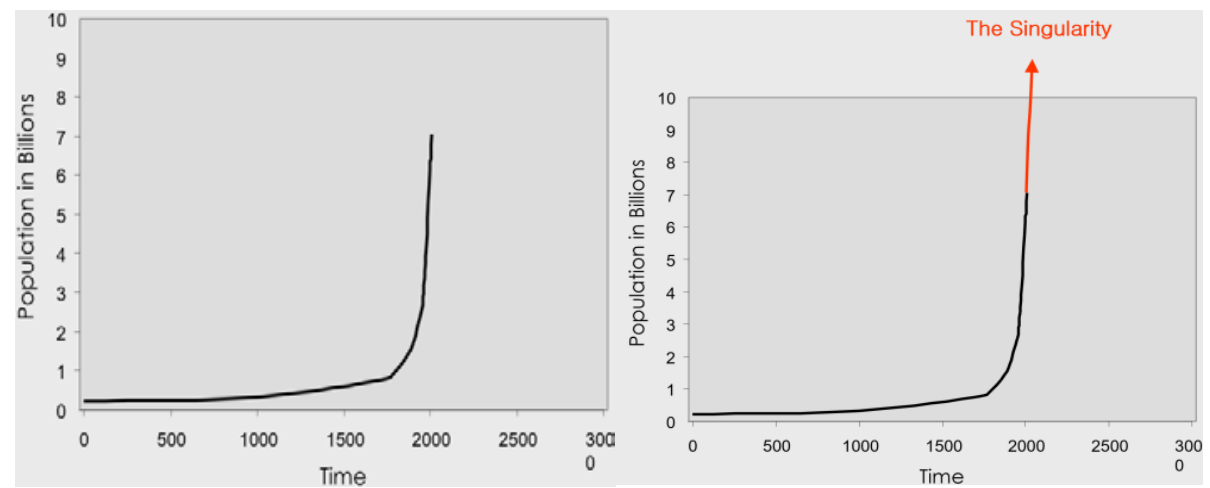

Figure 1. Population change since the Early Stone Age and the Singularity of increasing population

If we look at this growth, we see a Singularity - the equations for superexponential growth imply an event horizon of sorts where population appears to be growing infinitely. So if populations keep on growing like the figure shows (Figure 1), what will we be confronted with - infinite population growth, immortality, or zero population growth? Will an evident tipping point be reached. Many researchers have tried to answer this question and some forecast the date where human population will approach infinity. The real situation is different however for our human population is slowing to a steady state, which is the demographic transition while more and more people are living in cities. This convergence is shown in Figure 2. World population will not grow to infinity but is likely to stabilise this century while at the same time most populations will live in cities of one size or another. So what happens when all the world's a city - will we still speak of cities? Of course, but this still poses an enormous and increasing problem about what a city actually is. But what is clear is that we will not all live in one giant city. In fact the really giant cities are a decreasing proportion. Since 1975, the smaller big cities are increasing (Batty, M \& Marshall, 2017).

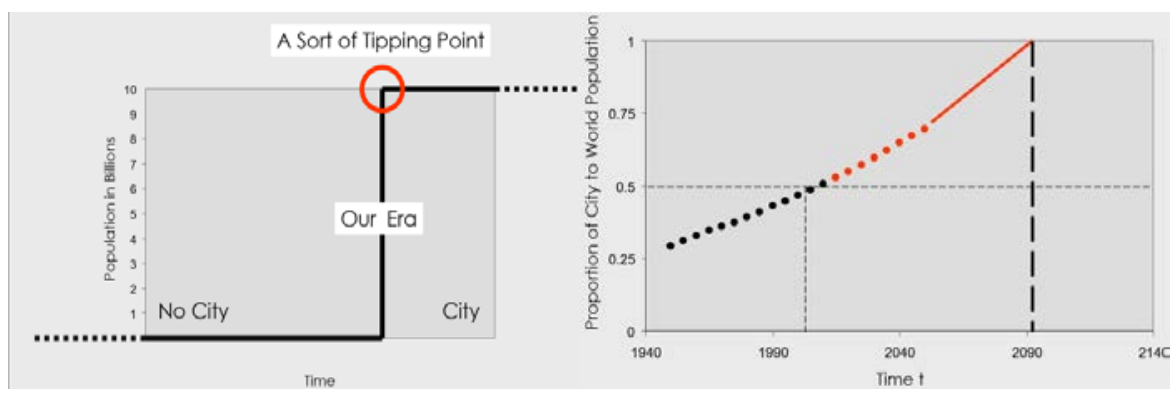

Figure 2. The demographic transition accompanying with population growth

If you wish to explore this question further, then please look at my book Inventing Future Cities which is online and available in Chinese. http://spatialcomplexity.blogweb.casa.ucl.ac.uk/files/2020/10/Batty- 人工智 能和可计算的城市-.pdf There we show how important it is to be very careful about defining the boundaries of cities as this whole question depends on how we make distinctions between cities of different sizes and even whether this distinction is meaningful any more (Batty, 2018) 


\section{FORM AND FUNCTION - ENERGY, INFORMATION, CONNECTIVITY, NETWORKS}

As shown in the left hand picture of Figure 3, this to some extent impresses on you the difficulties of defining the boundaries of a city. If you research the physical form of London, you will find the urban boundary is hard to recognize, and this complicates the city size distribution. Just as the right picture shown in Figure 3 reveals, it illustrates that the city size distribution of British cities loosely follows a power law. The reason I say loosely is that we are not very clear about how big the whole urban system is. For example we cannot define US cities by leaving out Canadian cities, because they are part of the same urban system all along the border, and when we come to look at Britain there is even an argument that all the cities in the country are part of one big megalopolis. In short, city definition is notoriously difficult.
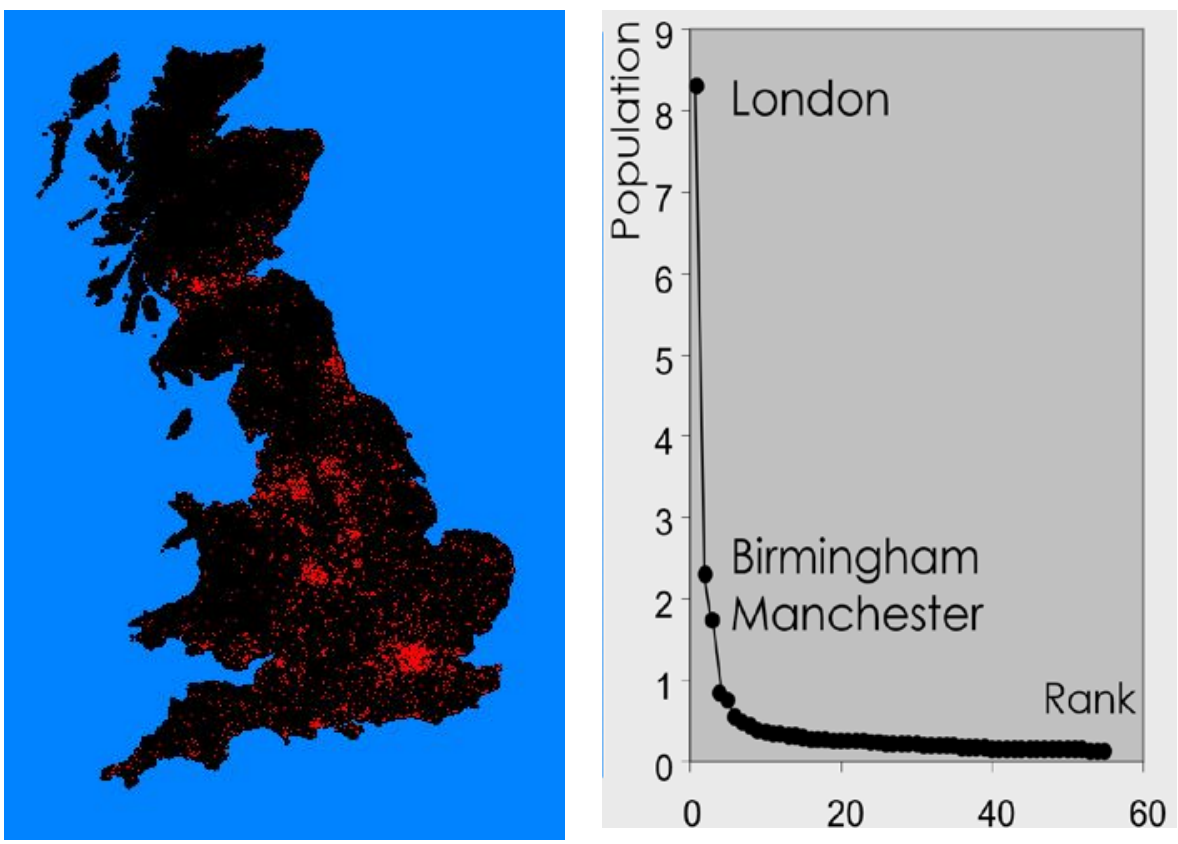

Figure 3 . The spatial pattern of the UK and its city sizes
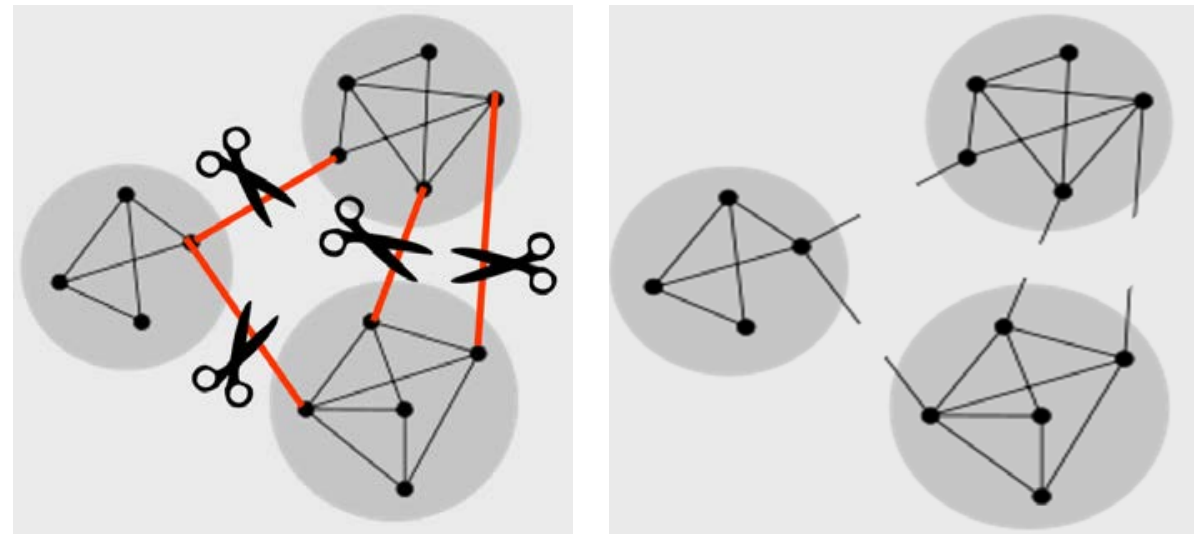

Figure 4. The conceptual flowchart of partitioning a network into clusters

In such situation how can we define form and function? We should define cities that take account of their connectivity. This builds on network theory and basically takes the street network and its clusters. It uses 
techniques from physics which are part of percolation theory. Imagine we have a little network and we want to define clusters, then let us cut the longest links, those that are greater than a given distance threshold so that we partition the network into clusters. And of course, we can keep on doing this successively pruning the network as we show above in Figure 4. We now have excellent digitised transport networks, such as the UK Ordnance Survey master map, the crowdsourced Open Street Map, and so on, and we can define various flow data within city systems through big data. We are developing this method for many places and at many scales. We have very elaborate movies of millions of clusters for Europe, America and so on. We can also generalise this definition to problems inside cities. To identify what is a neighbourhood, is as problematic as defining a city. Here is Abercrombie's iconic map of London neighbourhoods in 1944 which we show in Figure 5.

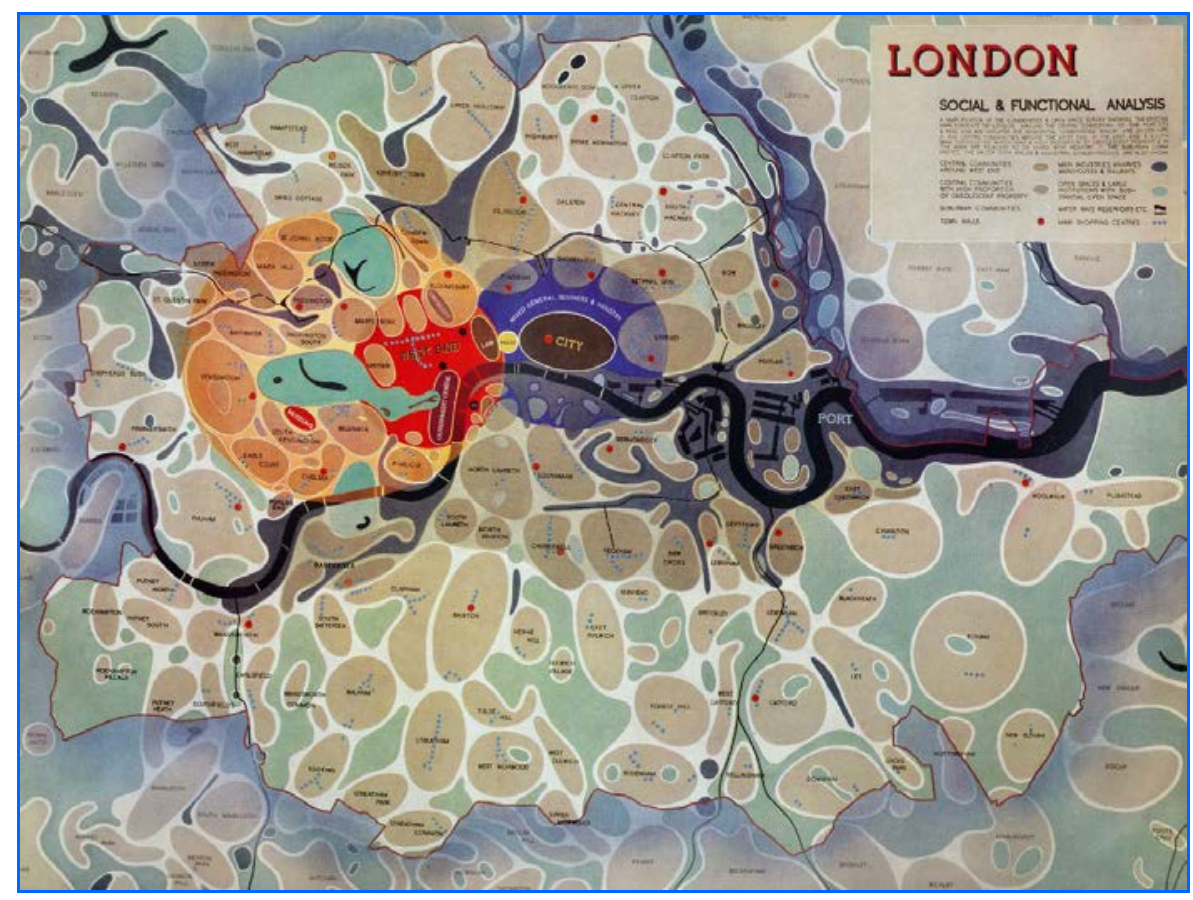

Figure 5. Abercrombie’s iconic map of London neighbourhoods in 1944

\section{THE HIGH FREQUENCY CITY: BIG DATA AND SMART, REAL-TIME CITIES}

Let me change tack and now focus on the 24 hour city and the kind of data related to this. I define big data with respect to its size but pay particular attention to the fact that the data I am referring to is urban data, that is, data for cities that are invariably tagged to space and time. I argue that this sort of data are largely being streamed from sensors, and this represents a sea change in the kinds of data that we have about what happens where and when in cities (Batty, M, 1997, 2007). I describe how the growth of big data is shifting the emphasis from longer term strategic planning to short-term thinking about how cities function and can be managed, although with the possibility that over much longer periods of time, this kind of big data will become a source for information about every time horizon (Batty, M. et al., 2012). 
Much of this new data is being generated in real time and one is able to get the complete data, not a sample. But there are many limitations: the data does not have much structure (Kitchin, 2014b). Transit data on fixed systems is perhaps the easiest to explore. We have developed several analyses of such data from smart card use for pricing - using our RFID Oyster card data which records where people start and finish their trip on bus or subway in London. This is a massive data set where 3 months of data generates billions of records.

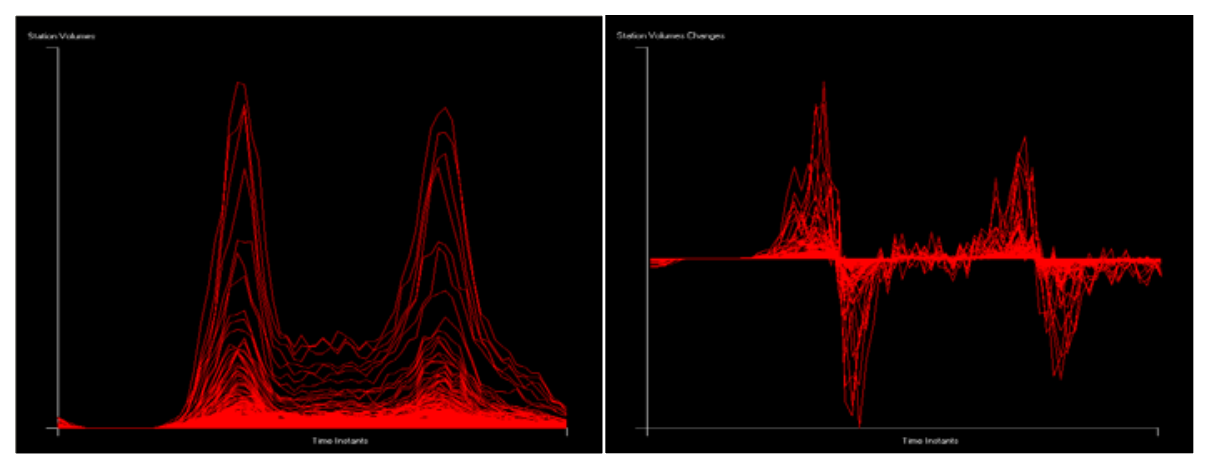

Figure 6. The heterogeneity and travel frequency in London revealed by Oyster card data

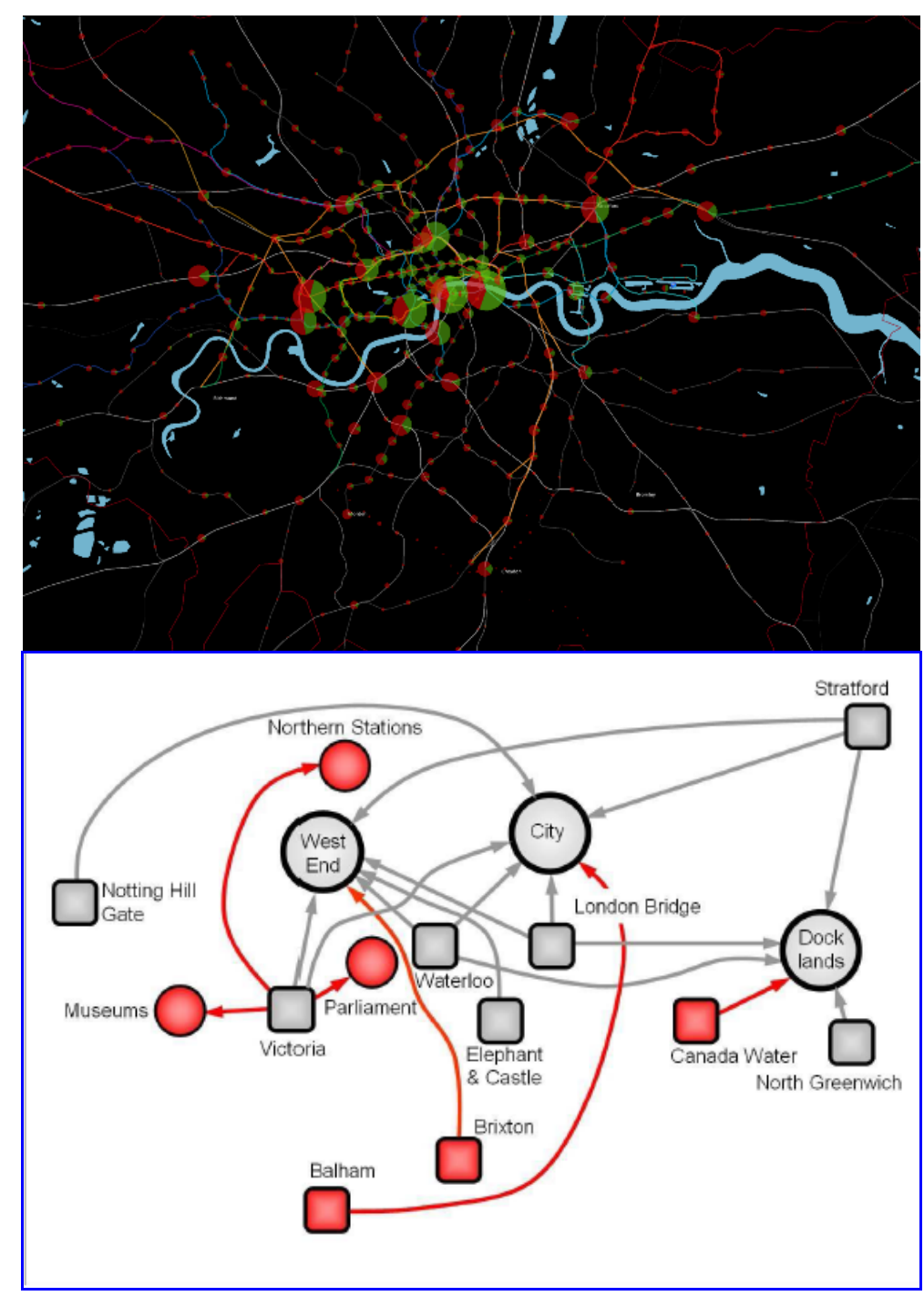

Figure 7. The urban structure interpreted from the travel data at London stations 
We can use these data to reveal the heterogeneity and travel profiles, as shown as Figure 6, where we see travel flows in London with morning and evening peaks together with a small blip (peak) around 10pm at night. We are also be able to interpret the urban structure from the data at the stations as we show in Figure 7. Currently what we are able to do with the Oyster data is assign it to lines and then to close stations and lines and figure out where passengers might divert to. In short, matching the demand data to the network is possible and is being attempted, but matching it with supply data is almost impossible. Diversion behaviour of travellers is also tricky as people can walk between stations and bus stops, and there is considerable analysis needed to indicate how people might change mode of travel from one network to another - either for making a straightforward trip or in the case of a disrupted trip. These are massive challenges that will require new theories about how people behave in such situations at a very fine spatial scale.

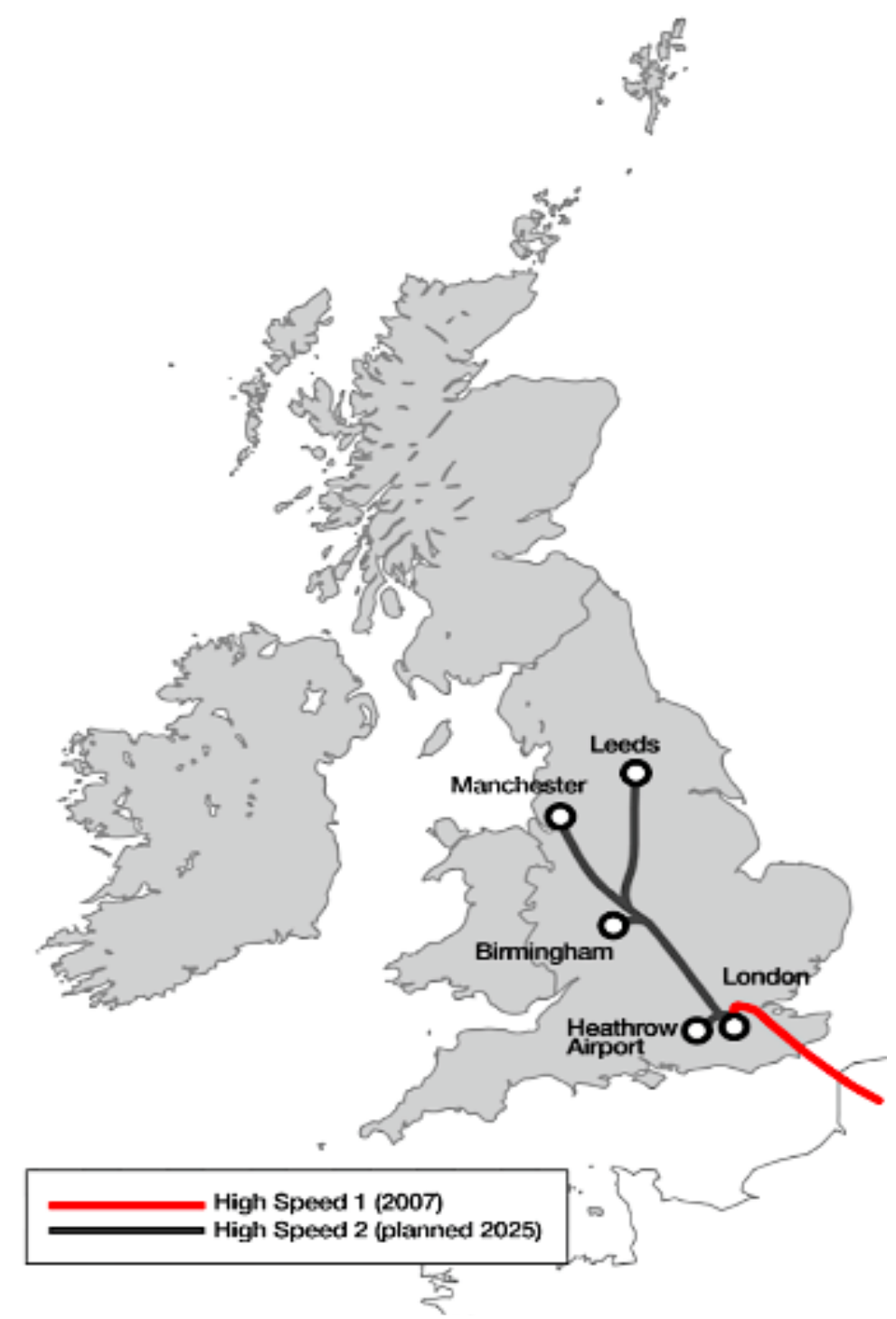

Figure 8 . The planned new railway - High Speed-2 - in the UK 


\section{TOOLS \& TECHNIQUES FOR PLANNING}

What can we do with this new science? Well there are many things. First and foremost it makes us think about how our understanding which is limited by the scale and the boundary issue I mentioned in the second section. Second it makes us think about what we can and cannot generalize. Are there laws out there to be discovered? I personally think not but there are those who adhere to some of these ideas who do. Third it injects a degree of criticality into our thinking - these tools cannot be applied blindly - one needs to think them through (Batty, M, 2010, 2018). And last but not least we can turn them into tools or models if you like. We are now scaling our traditional urban models of 40 years ago which have developed a lot in the interim of course to entire countries and mega-regions. Now we are building them for the UK, at least for England and Wales. They are all web-enabled, you can run them from anywhere. And we have just tested the impact of a new railway line on the country (Figure 8). The results show that the new railway will improve travel times of trips quite remarkably (Figure 9) and also result in population change (Figure 10). This is surprising in that before we used these new models, we did not expect the impact to be so great. It is imperative that such tools must be used more and more deeply in planning practice to support planner and decision-makers making decision on policies (Kitchin, 2014a).

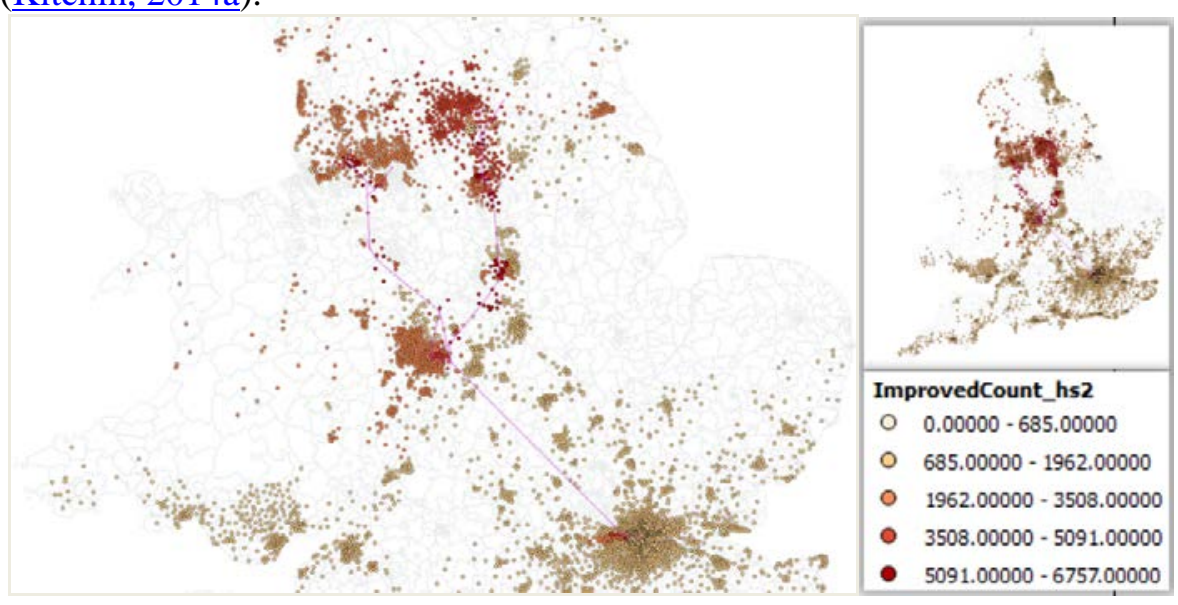

Figure 9. Forecasting improved trips produced by New High Speed railways up until 2035

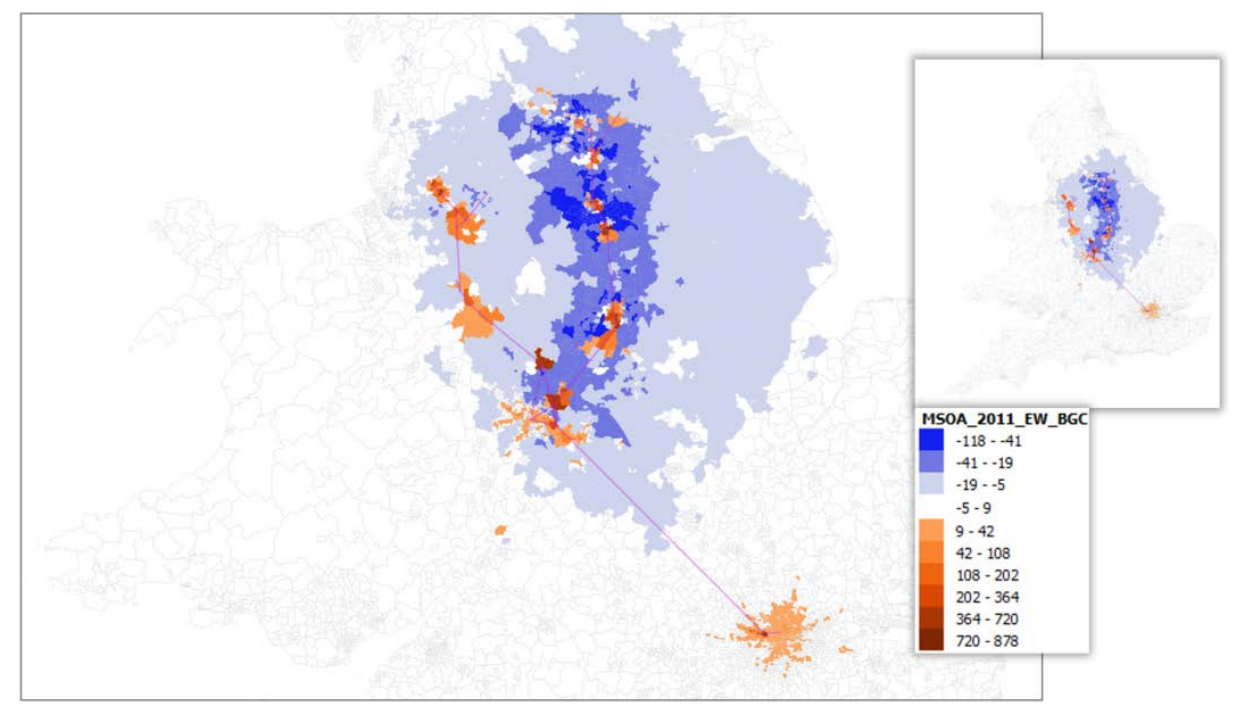

Figure 10. Forecasting population change affected by the planned new railway 
This short summary of my lecture I hope will give you some idea of the new tools that planners now have at the disposal to begin to think systematically about the future of cities and urbanisation. Many of these tools are under constant development and many applications of them are now being made all over the world. We need to consider ways in which we can organise this great archive and armoury of models so that we can best utilise them in different situations.

We need to define appropriate conditions under which such models might be used and we need to consider that more than one model - indeed many different models - might be used in a single situation. No one model is the right one and this we need to get used to the ways in which many models might be used in different situations. This then is the challenge that we face in developing a new science of cities.

\section{REFERENCES}

Batty, M. (1997). "Virtual Geography". Futures, 29(4-5), 337-352.

Batty, M. (2007). Cities and Complexity: Understanding Cities with Cellular Automata, Agent-Based Models, and Fractals. The MIT Press.

Batty, M. (2010). Urban Modelling: Algorithms, Calibrations, Predictions. Cambridge University Press.

Batty, M. (2018). Inventing Future Cities. Cambridge, MA: The MIT Press; and

http://spatialcomplexity.blogweb.casa.ucl.ac.uk/files/2020/10/Batty-人工智能和可计算的城 市-.pdf

Batty, M., Axhausen, K. W., Giannotti, F., Pozdnoukhov, A., Bazzani, A., Wachowicz, M., Portugali, Y. (2012). "Smart Cities of the Future". The European Physical Journal Special Topics, 214(1), 481-518. doi: 10.1140/epjst/e2012-01703-3.

Batty, M., \& Marshall, S. (2017). "Thinking Organic, Acting Civic: The Paradox of Planning for Cities in Evolution". Landscape and Urban Planning, 166, 4-14. https://doi.org/10.1016/j.landurbplan.2016.06.002.

Kitchin, R. (2014a). "Big Data, New Epistemologies and Paradigm Shifts". Big Data \& Society, 1(1), 1-12. doi: 10.1177/2053951714528481.

Kitchin, R. (2014b). "The Real-Time City? Big Data and Smart Urbanism". GeoJournal, 79, $1-14$.

Sassen, S. (2017). "How the Powerless Can "Hack” Global Cities". The Architect's Newspaper. https://www.archpaper.com/2017/08/saskia-sassen-hack-global-cities/ 